\title{
The geometrical headache of French policies: Can vertical cultures be tilted horizontally?
}

\author{
Thomas Saïas \& Cécile Delawarde \\ Paris, France
}

Thomas Saïas, Ph.D., is associated professor of psychology at Université du Québec à Montréal (Canada), research fellow at Université Paris-Descartes (LPPS, IUPDP) and president of the French Community Psychology Association.

Cécile Delawarde, M.Ps., is Ph.D. candidate in mental health sociology at Université Paris-Descartes (CERMES3), Paris, France.

Keywords: Social Policies, Public Health, Communities, Health promotion, Social change, Knowledge, France.

Recommended citation: Saïas, T. Delawarde, C. (2013). The geometrical headache of French policies: Can vertical cultures be tilted horizontally? Global Journal of Community Psychology Practice, 4(2), xx-xx. Retrieved Day/Month/Year, from (http://www.gjcpp.org/). 


\title{
The geometrical headache of French policies: Can vertical cultures be tilted horizontally?
}

\begin{abstract}
French governmental policymaking operates by top-down processes of decision-making, jeopardizing all forms of power transfer and social transformation. The technocratic structure of public health promotes cost-effective, evidence-based curative and preventive strategies, focusing on individuals rather than on contexts. On the other hand, field workers, whose theoretical orientation is based mainly on psychoanalysis and individual clinical practices, are as reluctant as policymakers to move towards community practices and power sharing processes.

This paper is based on our work as a community psychologist, working in a French governmental agency, and as a sociologist of mental health studying the processes of political decision-making in regard to preventive public health policies. The objective is first to reflect on the distinctive aspects of governmental policymaking in our country, and second, to underline the obstacles to and facilitators of success in our social policy-related work.

In our context, we propose that community psychologists act in order to (1) apply social science knowledge and contextualize actions, with the intention to help political decision-making by including environmental, social and community variables in the definition of human processes and behaviors; 2) criticize the top-down decision-making process and the focus on the individual, by developing an interactionist model of knowledge evaluation, which would allow vertical understanding and decision-making to tilt horizontally, and 3) support people to create legitimate knowledge from their contexts rather than empowering them through psychological interventions.
\end{abstract}

Keywords: Social Policies, Public Health, Communities, Health promotion, Social change, Knowledge, France.

\section{Introduction}

French governmental policymaking is characterized by ambivalence with regard to the inclusion of community dynamics in social, health and family policies. Although multiple recent publications have acknowledged the importance of community-related practices (social inclusion, health promotion, community development, etc.) for reaching social objectives (e.g. Centre d'Analyse Stratégique, 2009; Délégation Interministérielle à la Ville, 2007), the structure of public services and political decision still relies on governmentally-led processes, where intermediate structures (such as associations, cities, etc.) can only have limited power. This lack of coherence between the political discourse (sharing power with communities) and the actual organization of the French system jeopardizes the possibility of a new social organization.

In 2012, a symposium was organized by Kenneth Maton during the $4^{\text {th }}$ International Conference on Community Psychology in Barcelona, Spain, with the intention of highlighting similarities and differences in community psychology practices in the policy domain in countries from four different continents.
This paper, based on our presentation, describes our work as a community psychologist, working in a French governmental agency (TS) and as a sociologist of mental health studying the processes of political decision making in regard to preventive public health policies (CD).

Specifically, we intend to reflect on the distinctive aspects of governmental policymaking in our country (France) and the obstacles to and facilitators of success in our social policy-related work.

1. The distinctive aspects of French governmental policymaking in social and health policies

Two elements are worth highlighting with regard to the French culture in social policies. First, the importance of the egalitarian structure of society and its impact on the processes of political decision, and second, the direct relationship between the individual and the State, ignoring the community level of decision making.

\subsection{The French egalitarian culture}


French democratic culture is quite recent. Although the French monarchy itself ended in 1848, with the beginning of the second Republic, the end of the second Empire and the start of the third Republic in 1870 initiated the last revolutionary republican movement, concretized by the fourth Republic in the immediate post-war in 1946, and the fifth Republic in 1958 which constitutes the current republican constitution of France.

In 1946, the French government initiated what could be considered the most important welfare state system worldwide. This structure, although designed to promote the health of the most vulnerable populations, was set upon a traditional, vertical model, in which the State was directly responsible for the individual's health and in direct contact with each citizen. The egalitarian model was then predominant (Becker, 2005).

The field of early childhood constitutes the most interesting example of this public health egalitarian paradigm. In 1945, the French government created the Maternal and Child Protection service (Protection Maternelle et Infantile, PMI), whose aim was to reduce child mortality through a universal prevention system, accessible to every new mother and her baby. Nowadays, its missions have expanded, and the PMI now offers midwifery, child nursing and medical services, as well as maternal and child mental health assistance, specifically through home visitation. Although these services still intend to reach all newborns and their mothers (and fathers), a recent evaluation of access revealed that less than $10 \%$ of families were accessing these services (DASES 75, 2003). Rather than focusing on reducing inequalities in access to health and social services by reaching individuals excluded from this system and modifying the institutional environments in order to provide more equal organizations, French public policies are now promoting the current system of universal prevention that favor people who can easily access these systems, creating thereby another form of inverse care law (Hart, 1971).

The egalitarian ideology in France can be seen as a positive force as well as a weakness. It is a positive force as it promotes the universality of a basic health service for an entire population. But, from a critical standpoint, it is also a weakness as it disempowers the communities, who remain dependent on governmental decisions. As a consequence this egalitarian system hinders the possibility of social change and a paradigmatical shift from equality to equity. In 1995, Alain Minc -a French economistwrote a report on equity for the government, arguing in favor of the development of an equitarian model to challenge the social consequences of the exclusive egalitarian political system (Minc, 1995). Following this publication, there was much criticism, linking it to an American (Rawls') model of public policies. Hence, instead of initiating a debate on the meaning of social justice, which could have emphasized that the French system was orientated towards utilitarianism (e.g. Nagel, 1973) rather than equitarian justice (Rawls, 1971), the most confusing dispute began, leading to pointless discussion about the way to think about the organization of public space (Dupuy, 1995).

By promoting the technocratic structure of public health, the current system empowers bureaucratic engineering, which is translated in our day by multiple recommendations promoting evidence-based curative techniques and evidence-based preventive strategies (e.g. Centre d'Analyse Stratégique, 2012; Haute Autorité en Santé, 2005; Ministère chargé de la santé, 2005, 2012; Mission interministérielle de lutte contre la drogue et la toxicomanie, 2008). A recent study targeting French professionals' views on the use of evidence-based "mental medicine" applied to parenting programs revealed that these technocratic powers -which were distributed within a broader public health paradigm- were in strong opposition to the anthropological, socio-political and interventional ethics of field professionals (Delawarde, Saïas, \& Briffault, submitted).

Regrettably, from our point of view, the disempowerment promoted by the technocratic world has occurred: although the democratic structure of our State is functional, French citizens appear to demand governmental interventions, rather than community development. The idea of a power transfer from State to populations/communities is universally interpreted as a possible withdrawal of governmental institutions, and the meaning of "community" is still interpreted as a neo-liberalist concept (for an illustration of the confusion, see Giampino \& Vidal, 2009), sustaining individual interventions for individuals in the community, rather than interventions $b v$ and for communities. Hence, populations and professionals are wary about engaging in formal community practices that could inflect vertical, linear top-down decision making into power sharing processes. This cultural misinterpretation of community development jeopardizes the investment towards intermediate forces such as communities, within the broad field of health democracy.

\subsection{The emphasis on the individual and the fear of community level interventions}


Between the State and individual level interventions, there seems to be no seat for community level interventions. It is only with huge difficulties that one can address the idea of a life within communities that can vary between communities, justifying adaptive and local policies.

For example, the principal governmental actions (and economic investment) in the field of parenting and family policies are (a) the universal-local but governmentally-led health service, the PMI and (b) the wide range of family benefits (for a total budget of $50 \mathrm{~b} € /$ year), resulting not in services, but in the direct economic dependence of families on the government.

Other local initiatives funded by public authorities (such as parent support groups, local associative actions, parent-child centers, etc.) are quite common and popular but remain disparate from one area to another, as (a) services do not benefit from a systematic qualitative evaluation process that would allow them to be identified at a national level and subsequently highlighted and (b) the contents of these services depend on individual initiatives. In any case, almost all of these local actions rest on structures that are administrated by practitioners. Although these structures often include volunteer workers (see below), their culture is still based on psychological/social work models of intervention, with only a few of them run through a power sharing process that effectively includes community members.

This emphasis on individual level intervention is particularly true within the field of health, prevention and health promotion. In contrast, French policies of the early 2000's emphasized the necessity of sustaining the development of local initiatives in health and social development. Within the national policies of local development (Politique de la Ville, which were developed in the 1970's to fight social and urban discrimination,) Jospin's socialist government created in 2001 a local institution (Ateliers Santé Ville) aimed at promoting global health within deprived territories (including, simultaneously, social, economic and health issues).

However, these structures which are now 12-years old have not yet succeeded in their ambition to promote the co-investment of communities and public services, to create supportive environments or strengthen community actions (i.e., the two wings of the WHO Ottawa Charter, ((1986), which constitutes a key reference for practitioners from this field). These efforts remain dependent upon professionals, who still receive a mainstream education in health and social services, excluding community development and power issues as themes of interest.

Nevertheless, a positive perspective is worth noting. In France, there are 1,300,000 active associations or NGOs and 13 million people are engaged at some point in these associations. $45 \%$ of French citizens over 18 are engaged--even by financial support--in at least one NGO and $32 \%$ of the French adult population participate directly in one or more NGOs. The global budget of NGOs in France represents 3\% of the GDP (i.e. 70b€) (Archambault \& Tchernonog, 2012). Community actions through NGOs, even though largely promoted since the 1901 law which regulates rules the associations in France, still lack recognition within the political world and are not socially valued as a mean of social change.

The objective for French community psychologists is to actively advocate for the promotion of the existing associative world so it can become a real intermediate social and policy-relevant force. The main issue is not citizen mobilization toward a common policy objective, as this is already sustained by the associative world. Our engagement consists in lobbying and acting within the political world to influence policy makers for whom power distribution is still seen as a threat. The objective is for citizens, practitioners and policy makers to be able to distinguish actions operated within the community (i.e., local public actions) and actions operated by and for the community.

\section{What are the obstacles to and facilitators of success in social policy-related work}

\subsection{The key epistemic challenge}

What aspects of the policy world can community psychologists (and the broader critical community) address when conducting social policy-related work? Our experience working in/for governmental institutions in the field of public health lead us to consider the importance of challenging the top-down process of decision-making, and the uniqueness of the evidence-based knowledge approach to policy decision-making.

Following the footsteps of many market economy democracies, numerous new policy initiatives have been taken in France during the last thirty years in order to rationalize the activity of health services. By implementing a system of classification of health services ("PMSI", inspired from the diagnosis-related group $^{1}$ ) in 1983 (Mauroy's socialist government), France has developed a system of activity-based

\footnotetext{
${ }^{1}$ See www.ahrq.gov
} 


\section{Global Journal of Community Psychology Practice}

payment sustaining the general functioning of health services (Le Lay, Launois, \& Chemali, 2006). In this system, prevention can only have a secondary role, behind more visible and financially attractive activities, and community actions cannot fit in this medical-centered model.

To support this culture of efficacy and efficiency, policy makers are now referring to the broad field of evidence-based knowledge, which now supports most of the decision-making in public health and public mental health (Delawarde et al., submitted). Various reports aimed at health policy planners and practitioners have recommended developing, disseminating and implementing prevention and promotion programs for which public health benefits and cost-effectiveness have been proven by "the conscientious, explicit and judicious use of current best evidence" found in the international scientific review of literature (World Health Organization, $2004,2005)$. This new public health ideal is based on a specific conceptualization of (mental) health and (mental) disorders, new types of instruments, research, organizations, interventions and orientations (Horwitz \& Wakefield, 2007) which are at the heart of multiple controversies and the creation of various action groups, regrouping practitioners, researchers and citizens (Action group "No failing grade in conduct for three-year-olds", 2011; Parazelli \& Dessureault., 2010; Suesser, 2010). This public health perspective, relying essentially on a biomedical approach, has been criticized for neglecting socioeconomic, environmental, cultural and structural factors related to individual functioning.

Ironically, so-called "evidence-based" interventions focusing on individuals (the only level that allows systematic evaluation) and aiming at reducing individuals' risk factors and promoting individuals' strengths consistently refer to the Ottawa Charter's values, arguing that promoting individuals' competencies is the way to promote health in the general population.

This reduction of (technocratic) communityorientated values such as those presented in the Ottawa Charter to individual-oriented actions is now common and reflects a major rhetorical problem that community psychologists must question and fight. We must address this process by emphasizing the importance of promoting human capital and ecological capital vs. economic capital and by looking at all epistemic challenges that arise from the power-knowledge irreducible link (Foucault, 1975; Fryer \& Laing, 2008).

Thus, the key challenge in our work as community psychologists or clinical sociologists is to address issues related to power and status quo through knowledge and to change our practices towards the production of knowledge from communities, rather than the use of pre-defined political and scientific knowledge to develop actions seeking to empower individuals within communities.

\subsection{Keys to success: focusing on knowledge shifting rather that acting upon mainstream models}

\section{Creating and bringing social knowledge}

As we have seen, the functioning of governmental institutions, often characterized by an active process of status quo, is organized so that technocracy is preserved (limiting actions to the mainstream models of public health, centralizing political decision making). Power distribution to populations and communities is not a part of the agenda and consultation is preferred to co-decision.

We reject the view that illness, mental illness or positive mental health conceptualizations can only be founded upon a unifactorial prism which can only be justified by the possibility of being evaluated. One could compare this positivist political attitude to the Robert McNamara fallacy $^{2}$ :

\section{"The first step is to measure whatever can be easily measured. This is $O K$ as far as it goes. The second step is to disregard that which can't be easily measured or to give it an arbitrary quantitative value. This is artificial and misleading. The third step is to presume that what can't be measured easily really isn't important. This is blindness. The fourth step is to say that what can't be easily measured really doesn't exist. This is suicide." (quoted by Handy, 1995 p.219)}

Health and social science professional must make use of their status to challenge this power distribution. First, they can systematically add environmental, social and community variables to the conceptualization of human processes and behaviors, and second they can refuse to focus only on individual-level processes, which lead to groundless decisions. In this context, social science expertise appears necessary, beyond biomedical and epidemiological knowledge, in order to contextualize actions and help political decision making by taking into account the sociocultural environment. Second, in contesting the ultimate top-down linear process of

\footnotetext{
2 In reference to the 1960's US Secretary of Defense Robert McNamara's belief that success in war was quantifiable
} 
public interventions, George Albee and David Fryer critically encourage the development of a public health psychology model, claiming that

"[...] successful intervention in particular individuals with particular psychological and emotional problems has no real effect on the incidence, or rate of new cases, of these problems in the general population. Psychotherapy and other forms of individual 'treatment' can sometimes reduce or eliminate phobias, anxiety, bizarre behavior, depression and social withdrawal in particular people but the rate of these conditions in the population does not reduce either, in fact they appear to be increasing [...] because at least some kinds of psychological and emotional problems can be socially addressed they might be socially preventable"(Albee \& Fryer, 2003)

Hence, the authors call for the development of public health (preventive) interventions in a sequential way that would start with actions targeting oppressive environments and ultimately, if not possible otherwise, by actions targeting individuals (see figure 1). The Albee and Fryer model constitutes a reference for critical professionals working for governmental health institutions.

Figure 1. Albee and Fryer's Public health psychology model (Adapted from Albee, G. and Fryer, D. (2003)).

\section{Reduce or prevent transmission of the noxious agent to the host}<smiles>[AlH2]</smiles>

Reduce or eliminate the noxious agent responsible

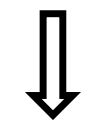

Strengthen the resistance of the host to the noxious agent

Promoting horizontal knowledge creation

Clinical sociologists and community psychologists must advocate to include co-elaboration of knowledge at the beginning of all decision-making processes.

The first step consists of the systematic identification of the three-legged knowledge model that applies to most public health concerns.

No model should be elaborated before all types of knowledge are investigated. Qualitative methods addressing this specific evaluation are integral to community psychology and clinical sociology and rely on the values of community action: recognition of the oppressive power of "science", social justice, active democracy, and related concepts.

In public health institutions, in addition to the recommendation of "combining the support for policy priority-setting with the dissemination of tools and evidence-based knowledge" (Jané-Llopis \&
Anderson, 2005, 2006), knowledge transfer through science-push models are promoted. Such models suggest that scientific knowledge should be easily accessible to practitioners and decision makers, and that researchers should make this knowledge easily available.

On the other side, public authorities advocacy for the development of science-pull models that would support policy makers and practitioners to answer specific problems is important for adding scientific knowledge to their understanding of specific situational contexts.

Community psychologists advocate for the development of an interactionist model of knowledge evaluation that effectively allows vertical understanding and decision-making to tilt horizontally (Chagnon \& Malo, 2006). It supposes:

- To take into account all the strata of the ecological model of the targeted phenomenon (and the three legs of the available knowledge); 
- To analyze the interactions between all the engaged actors and generate (a) a common understanding of the targeted phenomenon and (b) the conditions for use of this common knowledge;

- To analyze the potential iatrogenic effects of the use of available knowledge and corresponding solutions on the targeted phenomenon;

- To make this process of analysis available to all actors. Professionals' roles should only be to support the elaboration of the common knowledge through the stimulation of the interaction.

Knowledge and learning are understood here as social and contextual processes that can only take place and make sense in the specific situation that requires new information to pursue specific objectives. Knowledge is a social construct that should be linked with existing values and social structures which are legitimate in a specific context (Hemsley-Brown \& Sharp, 2003). This approach refers to the situated learning model (Lave \& Wenger, 1991).

\section{3. 'Knowledgementing' vs. 'Empowering' people: towards epistemological community practices}

With regards to what has already been pointed out, community psychologists and clinical sociologists must tackle knowledge-power issues in social politics as well as in local practices. In France, social work (Rouzel, 2001) and psychology (Nicolas, 2001) have been characterized by their affiliation to psychoanalysis and individual clinical practices. Hence, and with regards to our cultural experience, field workers are as reluctant as policymakers to move towards community practices and power sharing processes. In the field of mental health, local practices are not based on communities. Besides that, power issues are rarely addressed and mainstream mental health professionals constitute a powerful (medicine-like) lobby (Saïas, Delawarde, \& Briffault, Submitted for publication), although they frequently use a critical rhetoric to address the influence of health politics on health economy issues and its consequences (e.g. Gori \& Del Volgo, 2009).

'Knowledgementing', i.e., the co-production of legitimate knowledge, should be understood as a prerequisite for all interventions, but also as a mean to intervene. Knowledge production is at the core of community psychology goals.

As we use it, 'praxis' refers to an

ongoing, irreducible, collective process through which is enacted, in one and the same process, 'knowledgementing' (the construction and legitimation of knowledge claims), 'radical reflexivity' (the bringing to awareness and critical problematisation of interests served by what is thought, said and done by all relevant parties), and 'ideologically progressive social action' (the pursuit of emancipatory process and just outcomes and the contesting of 'external and internal' institutional oppression (Fryer \& Laing, 2008).

Community activists participating in the process of knowledgementing of communities must act to reveal knowledge from the ground up. This dynamic is opposed to both science-push and science-pull strategies, used to bring policymakers, researchers and practitioners together around mainstream actions.

In terms of specific actions related to the knowledgement process implementation, there is a large literature on communities of practices (Lave \& Wenger, 1991) as well as on knowledge building processes (Chagnon \& Malo, 2006). Most of these processes rely on socio-constructivist learning theories (Piaget, 1936; Vygotsky, 1934) and sociocultural learning theories (de Laat \& Simons, 2002), where the professional's is seen solely as a mediator between individuals and their environment, leading to knowledge creation.
Whereas social-constructivist perspectives make a distinction between individual cognitive activities and the environment in which the individual is present, the socio- cultural perspective regards the individual as being part of that environment. Its supporters point out that learning cannot be understood as a process that is solely in the mind of the learner (Van Boxtel, 2000). Knowledge is distributed over mind, body, and its surroundings (Hewitt \& Scardamalia, 1998) and is constructed in settings of joint activity (Koschmann, 1999) (de Laat \& Simons, 2002)

Hence, contextual learning strategies imply a series of tasks and activities that can be followed by moderators (professionals, of community members) in order to promote interactions between real-life knowledge, situated in environments and the tacit knowledge of the learners (see for example Herrington \& Oliver, 1995).

On the other hand, knowledgement, as knowledge production, can rely on knowledge building 
strategies, aiming at empowering people so that they are "able to participate in the creation of new knowledge as a normal part of their lives" (Scardamalia \& Bereiter, 2003). In this model, and relying on communities, individuals should be provided with already-known knowledge before being encouraged and supported to formalize their own tacit and experimental root-based knowledge, so that new knowledge can be created or existing knowledge modified (which "lives in the world") (Scardamalia \& Bereiter, 2003). Again, an important literature has been generated in educational sciences to support practitioners and community members in their efforts to develop a knowledgment process.

Policymakers, researchers and practitioners' interests, while different in appearance, share underlying commonalities as regards the knowledge-power issue. Analyses of the activities of clinical sociologists and community psychologists must then focus on:
- The knowledgement process (vs. individual empowerment)

- The respect of the three-legged knowledge model (see figure 2), with a critical approach. From our point of view, criticism must not be applied as a means to deconstruct knowledge, but to analyze its construction, its use and the interests behind its use.

Hence, local practitioners, together with policymakers and researchers should be important targets for community psychologists. A critical approach to power issues should be developed in professionals' education. Knowledge revelation models should be promoted at all stages of the development of local practices. Finally, community psychologists should address all ideologies and support knowlegement through a co-constructive collective praxis.

Figure 2. Three-legged model of knowledge in public health

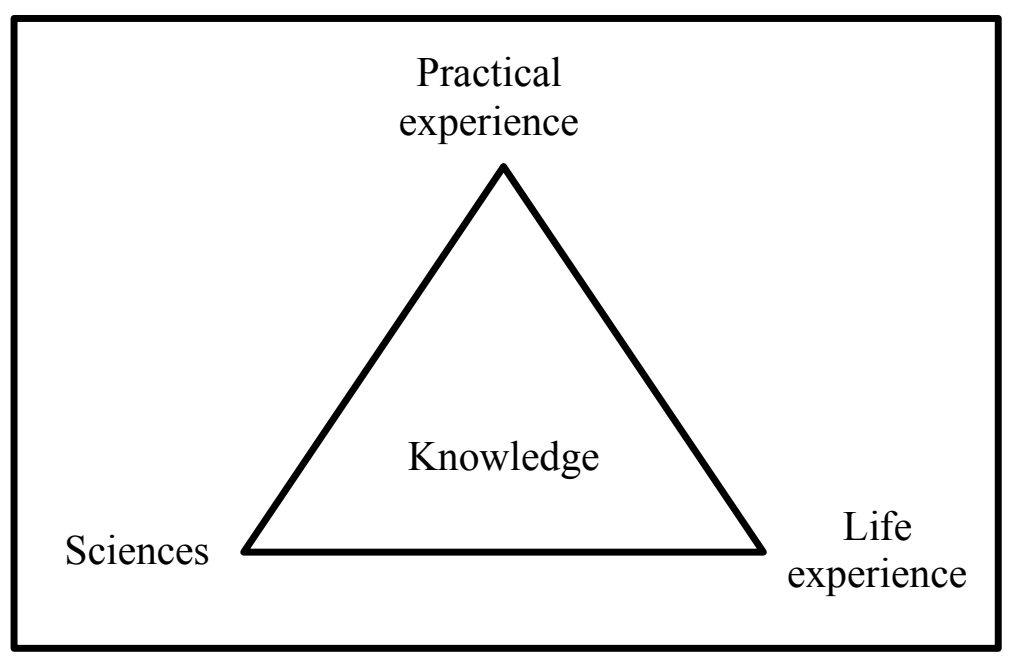

In promoting social change as an objective for social policies, one last challenge is to shift from so-called direct "interventions" through mass campaigns to indirect interventions providing community activists with frames helping them knowledgementing and gathering people, acting and evaluating and, hence, acting against scientific and political oppression and disempowerment.

\section{Conclusion: Cleaning up our own backyard and going forward critically, but responsibly}

Beyond our critical rhetoric, as community psychologists we must start by cleaning our own backyard(s).
Mainstream North-American community psychology has long been criticized by critical and radical community psychologists, contesting its monocultural vision and use of scientific knowledge uncritically, reinforcing oppression and discrimination (Fryer \& Laing, 2008; Nelson \& Prilleltensky, 2005). Of note, most of the publications from the main Society for Community Research and Action (SCRA) journals refer to mainstream psychological models of intervention (health psychology, clinical psychology, social psychology). In these publications, community psychology shows little specificity with regard to any kind of critical or even ecological strategies of elaborating knowledge, intervention or evaluation. By modeling traditional 
psychology and individual health promotion strategies, these practitioners and researchers reinforce what they claim fighting: disempowerment and oppression.

Not only is there the problem of how this field (community psychology) sort of manages to exist in psychology with the traditional remnants that are still there and the traditional ties to clinical and medicine that are still there in some sense, but how an academician with the kind of things that an academic needs to do could also be a community psychologist-It seems to me almost a total contradiction in terms. You have to satisfy being an academic, an entire list of things to do to get ahead. Academics have been, as a group, as remote from the real world as any group you can think of. Community psychologists, on the other hand, have a mission really in their life to be connected with the real world. To do both of those things at the same time is a hell of a difficult job (Schneider, 2000).

Besides criticizing North-American community psychology, one should also be aware of the risks that critical and radical community psychology carry with their discourses. By radically contesting almost every form of active thinking or action, radical psychologists suggest that oppression starts with people speaking for other people. If this basic statement is contested, it may erode almost all possible actions. While looking for vertical structures to be tilted horizontally, one's motivation must rise, individually (selfishly?), before being critically transformed and redirected ethically (e.g., towards knowledgementing processes). Moreover, we have to be watchful that critical thinking does not stop us from changing social structures. Without being cynical while looking to infiltrate mainstream places of decision, community psychologists must serve as critical partners on whom one can rely to improve social structures. This implies respecting (while criticizing) other epistemological approaches, and adopting pedagogical attitudes that allows starting where people are to bring them to a critical thinking. Hence, it supposes sharing a common vocabulary and, from this, proposing other modes of thinking and, more importantly, other types of evaluation of community processes (evaluation allowing us to exchange with academics and policymakers): showing that community psychologists, even critical ones, are aware of social, economic and political considerations, looking beyond the simple political debate.
These activities will continually question the place of community psychologists as researchers and activists, who should not fight about ideology, but only try to carry the voices of the people who are oppressed and disempowered, so they can be knowledgemented, and able to participate themselves in the political and policy processes.

\section{References}

Action group "No failing grade in conduct for threeyear-olds". (2011). Children in squares : a prevention which doesn't seem right. Toulouse: Erès.

Albee, G., \& Fryer, D. (2003). Towards a Public Health Psychology. Journal of Community \& Applied Social Psychology, 13, 71-75.

Archambault, E., \& Tchernonog, V. (2012). Repères sur les associations en France. Paris: La voix du mouvement associatif.

Becker, J. (2005). Histoire politique de la France depuis 1945. Paris: Armand Colin.

Centre d'Analyse Stratégique. (2009). La santé mentale, l'affaire de tous. Pour une approche cohérente de la qualité de la vie. Paris.

Centre d'Analyse Stratégique. (2012). Aider les parents à être parents, Le soutien à la parentalité, une perspective internationale.

Chagnon, F., \& Malo, C. (2006). L'application des connaissances scientifiques à l'intervention auprès des jeunes et des familles : conjuguer savoirs empirique, clinique et expérientiel. Défi jeunesse, Revue du Conseil multidisciplinaire $d u$ CJM-IU, 12(3), 29-35.

DASES 75. (2003). La santé de la mère et de l'enfant à Paris. Evolution 1980-2002. Paris: Département de Paris - DASES - PMI.

de Laat, M., \& Simons, R.-J. (2002). Collective learning: Theoretical perspectives and ways to suppport networked learning. European Journal for Vocational Training, 27, 13-24.

Delawarde, C., Saïas, T., \& Briffault, X. (submitted). French professionals beliefs in regard to mental health prevention and promotion: the case of parenting support.

Délégation Interministérielle à la Ville. (2007). Ateliers santé ville - Une démarche locale pour la réduction des inégalités sociales et territoriales de santé. Paris: Editions de la DIV.

Dupuy, J. (1995). Egalité, équité et confusion. Libération, 27 février 1995. 


\section{Global Journal of Community Psychology Practice}

Foucault, M. (1975). Surveiller et punir, naissance de la prison. Paris: Gallimard.

Fryer, D., \& Laing, A. (2008). Community Psychologies: What are they? What could they be? Why does it matter? A Critical Community Psychology Approach. The Australian Community Psychologist, 20(2), 7-15.

Giampino, S., \& Vidal, C. (2009). Nos enfants sous haute surveillance : évaluations, dépistages, médicaments... Paris: Albin Michel.

Gori, R., \& Del Volgo, M.-J. (2009). La santé totalitaire : Essai sur la médicalisation de l'existence: Flammarion.

Handy, C. (1995). The Empty Raincoat: Making Sense of the Future. London: Random House UK.

Hart, J. (1971). The Inverse Care Law. The Lancet, 405-412.

Haute Autorité en Santé. (2005). Préparation à la naissance et à la parentalité. Recommandation pour la pratique clinique. Saint Denis: HAS Service communication.

Hemsley-Brown, J., \& Sharp, C. (2003). The use of research to improve professional practice : A systematic review of the literature. Oxford Review of Education, 29(4), 449-470.

Herrington, J., \& Oliver, R. (1995). Critical Characteristics of Situated Learning: Implications for the Instructional Design of Multimedia. In J. Pearce \& A. Ellis (Eds.), ASCILITE95 Conference Proceedings (pp. 253262). Melbourne: University of Melbourne.

Hewitt, J., \& Scardamalia, M. (1998). Design principles for distributed knowledge building processes. Educational Psychology Review, 10(1), 75-96.

Horwitz, A. V., \& Wakefield, J. C. (2007). The Loss of Sadness: How Psychiatry Transformed Normal Sorrow into Depressive Disorder (1 ed.): Oxford University Press, USA.

Jané-Llopis, E., \& Anderson, P. (2005). Mental Health Promotion and Mental Disorder Prevention. A policy for Europe. Nijmegen: Radboud University Nijmegen.

Jané-Llopis, E., \& Anderson, P. (2006). Mental health promotion and mental disorder prevention across European Member States: a collection of country stories. Luxembourg: European Communities.
Koschmann, T. (1999). Toward a dialogic theory of learning: Bakhtin's contribution to understanding learning in settings of collaboration. Paper presented at the CSCL'99, Palo Alto.

Lave, J., \& Wenger, E. (1991). Situated learning: Legitimate peripheral participation. Cambridge: Cambridge University Press.

Le Lay, K., Launois, R., \& Chemali, N. (2006). La tarification à l'activité ou la recherche de 1'efficience comme impératif déontologique à l'hôpital. La lettre de l'infectiologue, 21(2), 6272.

Minc, A. (1995). La France de l'an 2000. Paris: Rapport remis au Premier Ministre.

Ministère chargé de la santé. (2005). Plan Périnatalité 2005-2007

Ministère chargé de la santé. (2012). Plan psychiatrie et santé mentale 2011-2015.

Mission interministérielle de lutte contre la drogue et la toxicomanie. (2008). Plan gouvernemental de lutte contre les drogues et les toxicomanies 20082011.

Nagel, T. (1973). Equal Treatment and Compensatory Discrimination. Philosophy \& Public Affairs, 2(348-362).

Nelson, G., \& Prilleltensky, I. (Eds.). (2005). Community psychology: In pursuit of liberation and well-being. Basingstoke: Palgrave Macmillan.

Nicolas, S. (2001). Histoire de la psychologie. Paris: Dunod.

Parazelli, M., \& Dessureault., S. (2010). Prévention précoce, nouvelle gestion publique et figure d'autorité. Les politiques sociales, 1, 13-26.

Piaget, J. (1936). La naissance de l'intelligence chez l'enfant. Paris: Delachaux et Niestlé.

Rawls, J. (1971). A theory of justice. Harvard: HUP.

Rouzel, J. (2001). Du travail social à la psychanalyse. Nîmes: Les éditions du champ social.

Saïas, T., Delawarde, C., \& Briffault, X. (Submitted for publication). De la réaction à la transformation sociale : Une analyse du discours du collectif Pas de 0 de conduite pour les enfants de 3 ans.

Scardamalia, M., \& Bereiter, C. (2003). Knowledge Building. In J. Guthrie (Ed.), Encyclopedia of 
Education (pp. 1370-1373). New York: Macmillan Reference.

Schneider, S. F. (2000). Exemplars in community psychology [Video series]. In J. Kelly (Ed.). Chicago: University of Illinois at Chicago.

Suesser, P. (2010). Le mouvement Pasde0deconduite face aux déviations prédictives de la prévention psychologique. Bulletin de liaison de la Fédération des associations de familles monoparentales et recomposées du Québec (FAFMRQ), 35(1), 6-12.

Van Boxtel, C. (2000). Collaborative Concept Learning: collaborative learning tasks, student interaction and the learning of physics concepts: Universiteit Utrecht.

Vygotsky, L. S. (1934). Thought and Language. Cambridge: MIT Press.

World Health Organisation. (1986). The Ottawa Charter for Health Promotion.

World Health Organization. (2004). Prevention of Mental Disorders, effective interventions and politicy options. Geneva.

World Health Organization. (2005). Promoting Mental Health, concepts, emerging evidence, practice. Geneva. 